\title{
Peertechz
}

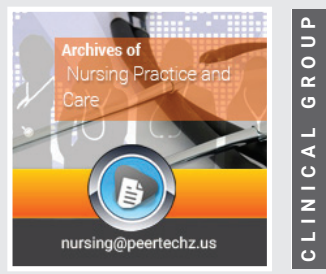

\section{Assessment of outdoor patient's satisfaction regarding clinical investigation of physicians in government hospitals of Quetta, Pakistan}

Received: 10 March, 2021

Accepted: 31 March, 2021

Published: 01 April, 2021

${ }^{*}$ Corresponding author: Maivand Khan, Faculty of Pharmacy and Health Sciences, Quetta, Pakistan, Tel:00923327976678; E-mail: khan_the_hellsangel@ hotmail.com, assad.pharmacist@gmail.com ORCID: https://orcid.org/0000-0002-9058-7735 Keywords: Patient satisfaction; Clinical investigation; Physician's attitude

https://www.peertechzpublications.com

Check for updates

\author{
Ali Nawaz', Anila Alam², Shah Dawood ${ }^{3}$, Musa Bin Bashir ${ }^{4}$, \\ Mirwais Khan ${ }^{5}$ and Maivand Khan ${ }^{1 *}$ \\ ${ }^{1}$ Faculty of Pharmacy and Health Sciences, Quetta, Pakistan \\ ${ }^{2}$ Sardar Bahadur Khan Women University, Quetta, Pakistan \\ ${ }^{3}$ Shaanxi University of Chinese Medicine, China \\ ${ }^{4}$ Xian Jiaotong University, China \\ ${ }^{5}$ Balochistan Institute of Psychiatry and Behavioral Sciences, Quetta, Pakistan
}

\begin{abstract}
Objective: The main objective of the study is to measurement of the satisfaction of Outpatient Department patients regarding clinical investigation of physicians in government hospitals of Quetta, Pakistan.

Methods: It was a cross sectional questionnaire based study. Data was collected from OPD (Outpatient Departments) of government hospitals (Sandeman provisional hospital, Bolan medical complex hospital) of Quetta, through a pre-structured questionnaire. Total sample size of the study was 447 . The data collected, was analysed by using IBM SPSS 22. The descriptive analysis was carried out for the demographic details as well as for other categories. All the data was categorical so was expressed as frequency and percentage.
\end{abstract}

Results: A total of 447 OPD patients were included in the study to know their perceptions towards the doctors and their attitude while consultation. Total of 550 questionnaires were distributed with the response rate of $89.4 \%$. It was found that most of respondents 270 (60.3\%) were male and having majority 338 (75.4\%) among the age group of 15 to 35 years. Majority 120 (26.8\%) respondents were satisfied that physician making them feel ease during physical examination. Among all 175 ( $39.1 \%)$ answered positively (Good) to physician guided you regarding any of dietary change.

Conclusion: This study reveals that there is a good satisfaction of patients regarding physician's attitude, diagnosis, treatment and advice in government hospitals of Quetta city.

\section{Introduction}

Patient satisfaction is one of the important goals of any health system, but it is difficult to measure the satisfaction and gauze responsiveness of health systems as not only the clinical but also the non-clinical outcomes of care do influence the customer satisfaction $[1,2]$. Patients' perceptions about health care systems seem to have been largely ignored by health care managers in developing countries. Patient satisfaction depends up on many factors such as: Quality of clinical services provided, availability of medicine, behavior of doctors and other health staff, cost of services, hospital infrastructure, physical comfort, emotional support, and respect for patient preferences [3,4]. Mismatch between patient expectation and the service received is related to decreased satisfaction $[5,6]$. Therefore, assessing patient perspectives gives them a voice, which can make public health services more responsive to people's needs and expectations $[7,8]$. 
In the recent past, studies on patient satisfaction gained popularity and usefulness as it provides the chance to health care providers and mangers to improve the services in the public health facilities [9]. Patients' feedback is necessary to identify problems that need to be resolved in improving the health services $[10,11]$. Even if they still do not use this information systematically to improve care delivery and services, this type of feedback triggers a real interest that can lead to a change in their culture and in their perception of patients $[12,13]$. Hence the present study is based on a comprehensive study conducted at Government hospitals of Quetta, Pakistan. To measure patient satisfaction who have availed services at outdoor patient department OPD.

\section{Materials and methods}

The study was a cross sectional questionnaire based study. The study has been conducted in the capital city i.e. Quetta of Balochistan, Pakistan. Data was collected from the Government hospitals of Quetta city by the approval of administration accordingly. For the desired purpose a questionnaire was developed. The questionnaire was developed after an invasive literature research and selecting the main factors that are supposed to be the main interacting questions among patient and the consultant. After gathering all the main factors, a questionnaire was developed as a first draft through the directives of my supervisor. After some necessary modifications to the initial draft, the foremost questionnaire was developed.

\section{Ethical consideration}

The study was conducted in consideration of ethical standards approved by the ethical committee of Pakistan (www.pmrc.org.pk/erc_guidelines). Consent form contained the approval for conduction of the current study from the Faculty of Pharmacy, University of Balochistan, Pakistan.

\section{Sampling technique}

The techniques for data collection are numerous in types. As there was no exact, validated and reliable data available regarding the data collection so convenience sampling technique is used for this study.

\section{Sample size}

The sample size selected for the study was depending upon the availability and accessibility of outdoor patients within the time period settled for data collection. The total sample size selected for the study was 550 depending upon the presence and accessibility. The process of cleaning was not required so the sample size included in this study was of 447 .

\section{Inclusion criteria}

The parameters selected to be included in this research study are as follows;

* All outdoor patients of selected government hospitals

* Male and female patients

* Patients him/ herself response

* Patient's more than the age of 15 years

\section{Exclusion criteria}

The parameters not to be included in this study are as follows;

* The patients from private hospitals

* Indoor patients

* Patients lesser than age of 15 years.

\section{Data analysis}

The data collected, was analysed by using IBM SPSS 22 . The descriptive analysis was carried out for the demographic details as well as for other categories. All the data was categorical so was expressed as frequency and percentage. Research were taken for the study purpose. A multistage sampling technique was used to select the respondents. A self-designed, pretested, semi structured questionnaire was developed to draw the patient's satisfaction to the health care services.

\section{Results}

\section{Demographic study}

The Table 1 represents the demographic characteristic of respondents. Total of 550 questionnaires were distributed and total sample collection is 447 with the response rate of $89.4 \%$. Result showed that most of respondents 270 (60.3\%) were male and having majority $338(75.4 \%)$ among the age group of 15 to 35 years. Majority $270(60.3 \%)$ respondents were married and $242(54.0 \%)$ were having Urban residency $111(24.8 \%)$ of respondents were having qualification level of intermediate. The occupation shown as $97(21.7 \%)$ of respondents was serving as private employee.

\section{Patients satisfaction characteristics}

Description: The Table 2 represents the characteristics of patient satisfaction relating to physician in various aspects. Among 447 respondents $262(58.5 \%)$ responded positively to a question regarding physicians' attitude. Majority 120 (26.8\%) respondents were satisfied that physician making them feel ease during physical examination. Physician informing you about severity of your disease was answered as Good by 124 (27.7\%) of respondents. Physician providing/ arranging better option of treatment for you was answered by 147 (32.8\%) of the respondents. Among all 175 (39.1\%) answered positively (Good) to physician guided you regarding any of dietary change.

\section{Discussion}

The study results highlight that patient satisfaction is positive. As most of the patients were satisfied by the physician's attitude, the proper time given to them by physician for their physical examination, diagnosis and treatment. In the current study the satisfaction level was influenced by marital status, main occupation, physical facilities, physician's service, nurses' service, pharmacy services, registration services, waiting time, service process, and working hours. The study indicated the areas for improvement from the respondents' 
Table 1: Demographic characteristics of respondents.

\begin{tabular}{|c|c|c|}
\hline Gender & Frequency & Percent \\
\hline Male & 270 & 60.3 \\
\hline Female & 178 & 39.7 \\
\hline \multicolumn{3}{|l|}{ Age Group } \\
\hline 15 to 35 years & 338 & 75.4 \\
\hline 36 to 55 years & 108 & 24.1 \\
\hline 56 and onwards & 2 & .4 \\
\hline \multicolumn{3}{|l|}{ Marital Status } \\
\hline Married & 270 & 60.3 \\
\hline Unmarried & 177 & 39.5 \\
\hline Divorced & 1 & .2 \\
\hline \multicolumn{3}{|l|}{ Residence } \\
\hline Rural & 206 & 46.0 \\
\hline Urban & 242 & 54.0 \\
\hline \multicolumn{3}{|l|}{ Qualification } \\
\hline No Education & 47 & 10.5 \\
\hline Primary & 27 & 6.0 \\
\hline Middle & 21 & 4.7 \\
\hline Metric & 66 & 14.7 \\
\hline Intermediate & 111 & 24.8 \\
\hline Graduation & 85 & 19.0 \\
\hline Post-Graduation & 80 & 17.9 \\
\hline Religious Education & 11 & 2.5 \\
\hline \multicolumn{3}{|l|}{ Occupation } \\
\hline Unemployed & 43 & 9.6 \\
\hline Own Business/ Self Employed & 87 & 19.4 \\
\hline Govt. Employee & 63 & 14.1 \\
\hline Private Employee & 97 & 21.7 \\
\hline House Wife & 73 & 16.3 \\
\hline Student & 79 & 17.6 \\
\hline Retired & 6 & 1.3 \\
\hline
\end{tabular}

points of perspective. Low patient satisfaction can lead to poor compliance with treatment and end up in poor health outcome. It has been noted that fifty-eight percent patients have a good satisfaction and this study is consistent with the study implemented by Asma Ibrahim in 2008 at India Gandhi Memorial Hospital, Male' Maldives only ten percent of 251 patients were highly satisfied. It revealed that the respondents' perceptions of the services were not good in term of convenience, scourges, and quality of care, hospital fee, and physical facilities. Particularly, the patients' opinion was mainly affected by the staff's attitude [14].

Patient satisfaction is a vital tool in evaluating the quality of the healthcare service in the outpatient department. In another study conducted on a sample of outpatient at Pakistan Institute of Medical Science, Islamabad by Anjum Javed in 2005 , out of 200 randomly selected patients, one hundred and eight had high level of satisfaction. Satisfaction level was said have significant relationship with distance from patient with the hospital and outpatient department timing. The study suggested that waiting time for service should be improved [15].

From these studies, it is evident that the satisfaction level of patients attending the outpatient department should be accessed periodically. The assessment of the services offered by is quite satisfactory. Physicians give satisfactory time for examination that is imperative tool for rational disease diagnosis.

This study also revealed that the majority of the physician tells about the severity of the disease and a good number of the physicians involve patients for start of their treatment they ask for their decision.

It is worrisome to note that there is poor satisfaction exist among patients regarding the arrangement of better option of treatment by Physicians, respondents were relatively good satisfied with physician that tell about the severity of the disease. Moreover, amount of prescribed drugs and the friendliness of the registering staff need to be improved. Last, education was proved to have significant relationship with patient.

\section{Conclusion}

Patient satisfaction surveys are essential in obtaining a comprehensive understanding of the patient's need and their opinion of the service receive; my study reveals that there is a good satisfaction of patients regarding physician's attitude, diagnosis, treatment and advice in government hospitals. They give proper time to the patients, have a good way to communicate patients and over all better counselling regarding any of dietary change and next visit while consultation.

\section{Recommendations}

The study findings suggest that following measures may be taken by the policy makers and hospital administrators to increase the patient satisfaction at public health facilities:

- Efforts should be made to reduce the patient load at the higher level facilities so that doctors can give more attention and time to the patients.

- Efforts are also needed to strengthen infrastructure and human resources at the lower level health facilities.

- The findings of the present study can be utilized to improve the services at public health facilities of the state resulting in the more satisfaction of patients availing such public health facilities.

- Such type of studies should be carried out in private hospitals as well as a comparative study so that government hospitals will be better in providing best facilities to patients.

- Further studies should be conducted to fill the gap among patient and physician.

- Study should be done on indoor patients as well. 
Table 2: Patient's satisfaction characteristics.

\begin{tabular}{|c|c|r|}
\hline Physician's attitude? & Frequency & Percen \\
\hline Good & 262 & 58.5 \\
\hline Very good & 70 & 15.6 \\
\hline Satisfactory & 72 & 16.1 \\
\hline Less than satisfactory & 19 & 4.2 \\
\hline Poor & 25 & 5.6 \\
\hline
\end{tabular}

Physician Making you feel with ease during physical examination?

\begin{tabular}{|c|c|c|}
\hline Good & 83 & 18.5 \\
\hline Very good & 73 & 16.3 \\
\hline Satisfactory & 120 & 26.8 \\
\hline Less than satisfactory & 76 & 17.0 \\
\hline Poor & 96 & 21.4 \\
\hline \multicolumn{3}{|c|}{ Physician Listening to you? } \\
\hline Good & 98 & 21.9 \\
\hline Very good & 67 & 15.0 \\
\hline Satisfactory & 100 & 22.3 \\
\hline Less than satisfactory & 78 & 17.4 \\
\hline Poor & 105 & 23.4 \\
\hline \multicolumn{3}{|c|}{ Physician Assessing your clinical condition? } \\
\hline Good & 99 & 22.1 \\
\hline Very good & 82 & 18.3 \\
\hline Satisfactory & 116 & 25.9 \\
\hline Less than satisfactory & 79 & 17.6 \\
\hline Poor & 72 & 16.1 \\
\hline \multicolumn{3}{|c|}{ Physician gives you proper time for examination? } \\
\hline Good & 80 & 17.9 \\
\hline Very good & 44 & 9.8 \\
\hline Satisfactory & 109 & 24.3 \\
\hline Less than satisfactory & 102 & 22.8 \\
\hline Poor & 113 & 25.2 \\
\hline \multicolumn{3}{|c|}{ Physician informing you about severity of your disease? } \\
\hline Good & 124 & 27.7 \\
\hline Very good & 54 & 12.1 \\
\hline Satisfactory & 123 & 27.5 \\
\hline Less than satisfactory & 73 & 16.3 \\
\hline Poor & 74 & 16.5 \\
\hline
\end{tabular}

Physician Involving you in decisions must be taken for your treatment?

\begin{tabular}{|c|c|c|}
\hline Good & 67 & 15.0 \\
\hline Very good & 91 & 20.3 \\
\hline Satisfactory & 81 & 18.1 \\
\hline Less than satisfactory & 91 & 20.3 \\
\hline Poor & 118 & 26.3 \\
\hline
\end{tabular}

Physician Providing or arranging better option of treatment for you?

\begin{tabular}{|c|c|c|}
\hline Good & 147 & 32.8 \\
\hline Very good & 103 & 23.0 \\
\hline Satisfactory & 90 & 20.1 \\
\hline Less than satisfactory & 58 & 12.9 \\
\hline Poor & 50 & 11.2 \\
\hline \multicolumn{2}{|c|}{ Physician briefed you for next visit? } \\
\hline
\end{tabular}

\begin{tabular}{|c|c|c|}
\hline Good & 116 & 25.9 \\
\hline Very good & 96 & 21.4 \\
\hline Satisfactory & 84 & 18.8 \\
\hline Less than satisfactory & 81 & 18.1 \\
\hline Poor & 71 & 15.8 \\
\hline
\end{tabular}

Physician Briefed you about Lab investigations, If any?

\begin{tabular}{|c|c|c|}
\hline Good & 122 & 27.2 \\
\hline Very good & 62 & 13.8 \\
\hline Satisfactory & 136 & 30.4 \\
\hline Less than satisfactory & 69 & 15.4 \\
\hline Poor & 59 & 13.2 \\
\hline
\end{tabular}

Did Physician check your previous reports and lab investigations?

\begin{tabular}{|c|c|c|}
\hline Good & 102 & 22.8 \\
\hline Very good & 89 & 19.9 \\
\hline Satisfactory & 92 & 20.5 \\
\hline Less than satisfactory & 98 & 21.9 \\
\hline Poor & 67 & 15.0 \\
\hline
\end{tabular}

\begin{tabular}{|c|c|c|}
\hline \multicolumn{2}{|c|}{ Physician guided you regarding any of dietary change? } \\
\hline Good & 175 & 39.1 \\
\hline Very good & 75 & 16.7 \\
\hline Satisfactory & 75 & 16.7 \\
\hline ess than satisfactory & 64 & 14.3 \\
\hline Poor & 59 & 13.2 \\
\hline
\end{tabular}

\section{References}

1. Agarwal D (2006) Health sector reforms: Relevance in India. Indian J Community Med 31: 220. Link: https://bit.ly/2PfCvXz

2. Singh S, Kaur P, Rochwani R (2013) Patient satisfaction levels in a tertiary care medical college hospital in Punjab, North India. Int J Res Dev Health 1: 172182. Link: https://bit.ly/3rGi6YT

3. Jenkinson C, Coulter A, Bruster S, Richards N, Chandola T (2002) Patients experiences and satisfaction with health care: results of a questionnaire study of specific aspects of care. Qual Saf Health Care 11: 335-339. Link: https://bit.ly/39xmdA7

4. Sodani PR, Kumar RK, Srivastava J, Sharma L (2010) Measuring patient satisfaction: A case study to improve quality of care at public health facilities. Indian J Community Med 35: 52-56. Link: https://bit.ly/3u6z8Re

5. McKinley R, Roberts C (2001) Patient satisfaction with out of hours primary medical care. Qual Health Care 10: 23-28. Link: https://bit.ly/3fxz758

6. Eisler T, Svensson O, Tengström A, Elmstedt E (2002) Patient expectation and satisfaction in revision total hip arthroplasty. J Arthroplasty 17: 457-462. Link: https://bit.ly/3rzHrDG

7. WH Organization (2000) The world health report: Health systems: improving performance, World Health Organization. Link: https://bit.ly/3cDdiPq

8. Rao KD, Peters DH, Bandeen-Roche K (2006) Towards patient-centered health services in India-a scale to measure patient perceptions of quality. Int J Qual Health Care 18: 414-421. Link: https://bit.ly/3wfH4BG

9. Batchelor C, Owens DJ, Read M, Bloor M (1994) Patient satisfaction studies: methodology, management and consumer evaluation. Int J Health Care Qual Assur 7: 22-30. Link: https://bit.ly/3mbBOu5

10. Baker DP, Day R, Salas E (2006) Teamwork as an essential component of 
high-reliability organizations. Health Services Research 41: 1576-1598. Link: https://bit.ly/2PgVJw1

11. Berry LL, Parasuraman A, Zeithaml VA (1994) Improving service quality in America: lessons learned. Academy of Management Perspectives 8: $32-45$. Link: https://bit.ly/2ObiXCZ

12. Boyer L, Francois P, Doutre E, Weil G, Labarere J (2006) Perception and use of the results of patient satisfaction surveys by care providers in a French teaching hospital. Int J Qual Health Care 18: 359-364. Link: https://bit.ly/31yR4rC
13. Nieva V, Sorra J (2003) Safety culture assessment: A tool for improving patient safety in healthcare organizations. BMJ Quality Safety 12: ii17-ii23. Link: https://bit.ly/3rHcdur

14. Ibrahim A, Chompikul J, Isaranurug S (2008) Patient satisfaction with health services at the outpatient department of indira gandhi memorial hospital male'maldives. Mahidol University. Link: https://bit.ly/3m6q7VK

15. Javed A (2005) 2005 Patient satisfaction towards out patient department services in Pakistan Institute of Medical Sciences, Islamabad.
Discover a bigger Impact and Visibility of your article publication with Peertechz Publications

\section{Highlights}

* Signatory publisher of ORCID

* Signatory Publisher of DORA (San Francisco Declaration on Research Assessment)

* Articles archived in worlds' renowned service providers such as Portico, CNKI, AGRIS, TDNet, Base (Bielefeld University Library), CrossRef, Scilit, J-Gate etc.

- Journals indexed in ICMJE, SHERPA/ROMEO, Google Scholar etc.

* OAI-PMH (Open Archives Initiative Protocol for Metadata Harvesting)

* Dedicated Editorial Board for every journal

* Accurate and rapid peer-review process

* Increased citations of published articles through promotions

* Reduced timeline for article publication

Submit your articles and experience a new surge in publication services (https://www.peertechz.com/submission).

Peertechz journals wishes everlasting success in your every endeavours.

Copyright: @ 2021 Nawaz A, et al. This is an open-access article distributed under the terms of the Creative Commons Attribution License, which permits unrestricted use, distribution, and reproduction in any medium, provided the original author and source are credited.

Citation: Nawaz A, Alam A, Dawood S, Bashir MB, Khan M, et al. (2021) Assessment of outdoor patient's satisfaction regarding clinical investigation of physicians in government hospitals of Quetta, Pakistan. Arch Nurs Pract Care 7(1): 015-019. DOI: https://dx.doi.org/10.17352/anpc.000055 